Sociohistórica

ISSN: 1852-1606

publicaciones@fahce.unlp.edu.ar

Universidad Nacional de La Plata

Argentina

\title{
El Movimiento Sindical de Base: apuesta sindical del PRT-ERP
}

\author{
Stavale, Santiago \\ El Movimiento Sindical de Base: apuesta sindical del PRT-ERP \\ Sociohistórica, núm. 46, 2020 \\ Universidad Nacional de La Plata, Argentina \\ DOI: https://doi.org/10.24215/18521606e110
}

Atribución no comercial compartir igual (CC BY-NC-SA) 4.0 
Artículos

\section{El Movimiento Sindical de Base: apuesta sindical del PRT-ERP}

The Grassroots Union Movement: PRT-ERP's union alternative

Santiago Stavale

DOI: https://doi.org/10.24215/18521606e110

Instituto de Investigaciones en Humanidades y Ciencias

Sociales, Facultad de Humanidades y Ciencias de la

Educación, Universidad Nacional de La Plata, Argentina

santiagostavale@gmail.com

Recepción: 24 Mayo 2019

Aprobación: 18 Noviembre 2019

Recepción: 24 Mayo 2019

Aprobación: 18 Noviembre 2019

\section{Resumen:}

Los años 70 en Argentina estuvieron signados por un proceso de radicalización política caracterizado por el surgimiento de un conjunto de fuerzas sociales, políticas y culturales que venían estructurándose desde los años 60 y que formaron el campo de la nueva izquierda. Entre ellas, se destacaron organizaciones políticas que, especialmente estimuladas por la revolución cubana y la crisis de legitimidad que vivía el sistema político argentino, se propusieron transformar revolucionariamente la sociedad por la vía de las armas. El presente artículo se propone analizar la experiencia del Movimiento Sindical de Base (MSB), herramienta sindical impulsada en la coyuntura del año 1973 por una de esas organizaciones: el Partido Revolucionario de los Trabajadores-Ejército Revolucionario del Pueblo (PRT-ERP).

Palabras Clave: Movimiento Sindical de Base, Clase obrera, PRT-ERP.

\section{Abstract:}

The '70s in Argentina were marked by a process of political radicalization characterized by the emergence of a set of social, political and cultural forces that had been structured since the ' $60 \mathrm{~s}$. These organizations shaped the new left's field. Furthermore among them were highlighted political organizations that, especially stimulated by the Cuban revolution and the crisis of legitimacy that lived the Argentine political system, they proposed to revolutionize society by way of arms. This article aims to analyze the experience of the Grassroots Union Movement (MSB), a union tool promoted in the conjuncture of 1973 by one of these organizations: the Revolutionary Workers' Party-Revolutionary People's Army (PRT-ERP).

KEYWORDS: Grassroots Union Movement, Working class, PRT-ERP.

\section{INTRODUCCIÓN}

Los años 70 en Argentina estuvieron signados por un proceso de radicalización política caracterizado por el surgimiento de un conjunto de fuerzas sociales, políticas y culturales que venían estructurándose desde los años 60 y que formaron el campo de la nueva izquierda (Tortti, 2014). Entre ellas, se destacaron organizaciones políticas que, especialmente estimuladas por la revolución cubana y la crisis de legitimidad que vivía el sistema político argentino, se propusieron transformar revolucionariamente la sociedad por la vía de las armas. Por tal razón buscaron entablar un vínculo con la clase obrera que promoviera su papel revolucionario, penetrando en las principales fábricas del país e interviniendo en las luchas sindicales. El estudio de este vínculo, entonces, adquiere una doble relevancia: por un lado ilumina aspectos de las mismas que han sido escasamente estudiados al verse opacados por la centralidad que adquirió el problema de la lucha armada y la violencia política en la producción académica sobre los $70 \mathrm{y}$, por el otro, permite comprender los alcances y los límites que tuvieron estas experiencias en su afán de representar y dirigir a la clase obrera argentina.

No obstante, en el último tiempo ${ }^{1}$ se ha planteado una agenda de investigación más sistemática que busca profundizar el estudio de la relación entre clase obrera y nueva izquierda (Basualdo y Lorenz, 2012; Rot, 
2016) y, en ese camino, han surgido trabajos que se dedicaron a reconstruir la experiencia del sindicalismo clasista y de movimientos de base a nivel de fábrica (Casco Peeble y Lenuda, 2016; Dawyd, 2017; Della Savia, 2017, 2018; Laufer, 2018), o bien directamente se ocuparon de estudiar la intervención política y sindical de las organizaciones de la nueva izquierda en el mundo obrero (Pacheco, 2015; Scoppetta y Torre, 2018; Stavale, 2017 y 2019).

En esa dirección, el presente artículo, que forma parte de una investigación de mayor alcance, se propone analizar la experiencia del Movimiento Sindical de Base (MSB), herramienta sindical de carácter frentista impulsada en la coyuntura del año 1973 por el Partido Revolucionario de los Trabajadores-Ejército Revolucionario del Pueblo (PRT-ERP). Más específicamente este trabajo busca identificar las condiciones en las que surgió dicho movimiento, los objetivos que se propuso y las características que fue asumiendo en la práctica. Además, en el marco de dicha reconstrucción, el artículo pone el foco en el rol que cumplió el PRT-ERP en el derrotero de dicha experiencia, como motor de su desarrollo y como responsable de sus limitaciones. Ello permitirá analizar la forma en que los perretistas concibieron a las herramientas frentistas y, también las dificultades y debates a los que se enfrentaron en dicha tarea.

\section{El MSB, LA RESPUESTA SINDICAL PERRETISTA A LA APERTURA DEMOCRÁtica}

Desde sus orígenes, el PRT-ERP definió a la clase obrera como el sujeto de la revolución socialista, y en función de ello concentró gran parte de sus esfuerzos en penetrar en las principales fábricas del país y participar activamente en sus conflictos enmarcándolos en su estrategia de "guerra revolucionaria". Así, se lanzó a construir células partidarias en las fábricas, y se propuso organizar agrupaciones clasistas que llevaran adelante una línea de lucha por la democracia y en contra de la "burocracia sindical" y espacios federativos que nuclearan a todas las expresiones clasistas y combativas. ${ }^{2}$ Sin embargo, en los primeros años de su desarrollo, motivado por la autoafirmación en la estrategia de la lucha armada, tendió a centrar la actividad partidaria en el accionar militar y a calificar a la actividad sindical como algo secundario, lo que, en los hechos, frenó su inserción en el movimiento obrero y postergó la construcción de herramientas de aquel tipo.

Esta situación cambió radicalmente en el año 1973. La apertura democrática y el retorno del peronismo al gobierno, concretado aquel año, inauguraron una nueva etapa política marcada por un cambio de las condiciones en las que se venía desenvolviendo la conflictividad política, social y sindical hasta entonces (De Riz, 1987; Lenci, 1998). Las condiciones democrático-legales y la legitimidad popular con la que asumió el nuevo gobierno significaron un desafío para todas las organizaciones de la nueva izquierda que se habían forjado al calor de la lucha contra la dictadura de la "Revolución Argentina".

En lo que respecta al PRT-ERP, la organización se vio obligada a definir su posición ante el nuevo gobierno, a resolver si continuaría o no con la actividad militar y a reorientar su trabajo en el movimiento obrero. Es que los perretistas caracterizaban a la apertura democrática como una "maniobra contrarrevolucionaria” que venía a aislar a las organizaciones revolucionarias, pero al mismo tiempo preveían que la extensión de las posibilidades legales y "semilegales" permitiría darle impulso a la intervención política de la organización y, fundamentalmente, fomentar la movilización de la clase obrera por sus reclamos más sentidos. ${ }^{3}$ Ya desde fines del año 1972 vaticinaban que la instauración de un gobierno peronista alentaría la lucha por las reivindicaciones inmediatas de los trabajadores, expresándose en una tendencia a "recuperar" sindicatos. ${ }^{4} \mathrm{De}$ modo que la fórmula con que decidió encarar el nuevo período y ordenar toda su intervención política fue la de aprovechar al máximo los intersticios legales pero sin abandonar la lucha armada. En ese sentido, se dispuso a lanzar herramientas político-organizativas que permitieran nuclear en su seno a amplios sectores del pueblo, disputando la dirección del movimiento obrero y popular. ${ }^{5}$

En lo que respecta al movimiento obrero, la proliferación de los conflictos obreros que le siguió al triunfo electoral peronista se transformó en una muestra de que las nuevas condiciones abrían un espacio político 
para transformar el descontento en protesta (Torre, 2004) y traducirlos en nuevos niveles de organización. Bajo esa realidad, la actividad sindical fue adquiriendo un lugar cada vez más importante en la política del PRT-ERP. Así, entre las principales definiciones del año 1973 figuraron la lucha por la independencia del movimiento sindical frente al gobierno, el apoyo "enérgico" a la movilización de los trabajadores por sus reivindicaciones gremiales, y promover un frente sindical nacional que centralizara las expresiones combativas y democráticas del sindicalismo a nivel nacional para disputar la dirección del movimiento obrero y oponer resistencia a lo que consideraban que sería la "ofensiva burocrática y gubernamental contra el clasismo". ${ }^{6}$ Así fue que impulsó el MSB, herramienta a través de la cual buscó hacer confluir diferentes corrientes político-sindicales y experiencias y activistas con trayectorias previas, con el fin de transformarlo en un polo de atracción nacional para el movimiento obrero.

\section{HACIA UN AMPLIO FRENTE SINDICAL.}

El MSB nació el 8 de julio de 1973 en el marco del “Primer Plenario Nacional por la Defensa y la Recuperación Sindical". Sin embargo tuvo como antecedente inmediato un acto clasista realizado en la Federación de Box de Buenos Aires el 14 de junio, organizado por el Instituto de Capacitación Obrera (ICO). ${ }^{7}$ La participación y la influencia del PRT-ERP en dicho encuentro y en la experiencia del ICO estuvieron motorizadas por la estrecha relación que la organización sostenía con Cerruti Costa, uno de sus fundadores, quien tenía comunicación directa con el Buró Político perretista. El acto se llevó adelante con aproximadamente 3.000 asistentes, y sus oradores principales fueron Antonio del Carmen Fernández, dirigente perretista y del ingenio tucumano San José, Jorge Álvarez Pardo del Sindicato de la Marina Mercante y Agustín Tosco. El primero de ellos hizo hincapié en desarrollar la democracia sindical desde las bases, mientras que el dirigente lucifuercista se ocupó de recuperar la experiencia de la CGT de los Argentinos, denunciar al Pacto Social y llamar a la unidad de todos los sectores revolucionarios, marxistas y peronistas.

Esta reunión fue la manifestación de un proceso organizativo que se venía gestando desde principios del año y que se cristalizó, como dijimos, en el plenario de julio. De este último, realizado en el salón de actos del sindicato Luz y Fuerza de Córdoba, participaron mil quinientos delegados en representación de 200 organizaciones de trabajadores de todo el país, entre las que se hallaban sindicatos, comisiones internas, comités de lucha y agrupaciones sindicales de Córdoba, de Gran Buenos Aires, Capital Federal, Tucumán, Salta, Jujuy, La Rioja, Santa Fe, Rosario, Paraná, etc. ${ }^{8}$ Entre los más destacados se encontraban los sindicatos de Luz y Fuerza y de Perkins, y el Movimiento de Recuperación Sindical de Córdoba, el Movimiento de Recuperación Sindical de SMATA Capital Federal, el Sindicato San José de Tucumán y la CGT de Salta. En el estrado, como parte de la Comisión Organizadora provisoria que presidía el encuentro, estaban Gregorio Flores, dirigente de FIAT y SITRAC y miembro del PRT-ERP; Leandro Fote miembro del Sindicato San José de Tucumán, también militante perretista; Roberto Campbell del sindicato de viajantes de Córdoba; Pérez del sindicato cordobés de Mercantiles; y López de Grandes Motores Diesel también de la ciudad mediterránea.

La reunión había sido convocada en un clima de alta tensión debido a la amenaza que había realizado la cúpula cegetista, encabezada por Rucci, de caducar el mandato de las CGT regionales a partir del 1 de julio, apuntando directamente a la central cordobesa. ${ }^{9}$ Esto se vio reflejado en la convocatoria al plenario en la que se denunciaba un plan organizado por "los sectores más reaccionarios de las 62 Organizaciones y grupos fascistas" que pretendía intervenir al gobierno cordobés y luego a todos los sindicatos combativos. ${ }^{10}$ El repudio a las amenazas cegetistas formó parte de la mayoría de los discursos y tuvo un lugar en el temario de la reunión, el cual giró en torno a cinco puntos: 
1. Caducidad del mandato de las CGT regionales y unidad del movimiento obrero; 2 . Por la plena vigencia de las comisiones paritarias; 3. Por la reincorporación de los despedidos por causas gremiales o políticas; 4. Por un salario vital, mínimo y móvil; 5. Tareas de organización. ${ }^{11}$

Gregorio Flores fue quien dio inició a la actividad plenaria remarcando la necesidad de que se respetara el carácter sindical del plenario y exhortando a los presentes a evitar transformarlo en un "deliberativo político" dominado por riñas entre las diferentes corrientes políticas que participaban del mismo. Esta advertencia respondía a la línea perretista de evitar sectarizar los espacios gremiales, y en ese sentido el plenario debía saber contener en su seno sin dificultades a "peronistas, radicales, socialistas, comunistas, marxistas y cristianos" que estuviesen de acuerdo con formar una alternativa combativa y antiburocrática al oficialismo cegetista. La participación en el plenario del Frente Revolucionario Peronista, a través de la CGT Salta, y de algunos sectores de la JTP (Salta, Jujuy y Avellaneda), como de otras organizaciones, era una muestra de que la apuesta frentista del PRT-ERP podía concretarse.

El plenario estuvo cargado de manifestaciones contra el Pacto Social -pilar del proyecto económico del gobierno peronista-, de denuncias a la "maniobra intervencionista" de la CGT nacional, de rechazo a la caducidad de la ley de convenios colectivos de trabajo y demás consignas antiburocráticas. El orador principal fue Agustín Tosco, como lo será en todos los actos públicos del MSB. En su discurso arremetió contra el Pacto Social y contra los intentos de intervención de los sindicatos combativos, e hizo un llamado a la unidad de todos los sectores antiburocráticos con permanentes alusiones a la necesidad de construir una "Patria Socialista" en Argentina para resolver los problemas de los trabajadores y el pueblo. Según las actas publicadas en Nuevo Hombre, Tosco habría sido elegido como miembro de la Mesa Provisora del MSB, constituida en el plenario, junto a Rivera (Construcción), Russo (Banco Cooperativo de Caseros), Pose (Metalúrgico), Roda (Gas del Estado, Capital), Flores (SITRAC), Fote (FOTIA), Pérez (Mercantiles- Córdoba), López (SMATA) y Barraza (Gráficos), Bolenein y Soria (San José, Tucumán). ${ }^{12}$ Como indican muchos autores (Pozzi, 2001; Iñigo Carrera, Grau, Martí, 2006; De Santis, 2010; Flores, 2013) la relación entre el PRT-ERP y el Tosco fue muy prolífica, sin embargo la mayoría indica que no habría participado formalmente ni del MSB ni del FAS. Nos arriesgamos a decir que probablemente se haya incorporado a la Mesa Provisora en una especie de "apadrinamiento" del espacio, papel que cumplirá efectivamente.

Entre las principales definiciones del plenario figuró, entre otras cosas, la construcción del MSB, con la tarea de editar un periódico y convocar a un nuevo plenario. Desde un inicio, el MSB se propuso ser una alternativa sindical democrática y antipatronal que, en oposición a la denominada "burocracia sindical”, disputara la conducción de los sindicatos y de la CGT, sosteniendo los principios de unidad para el movimiento sindical. En ese sentido sostenía la necesidad de una CGT única y no se proponía fomentar la formación de un sindicalismo paralelo (Mattini, 2007, p. 184).

Como lo sugiere su nombre, para el MSB los organismos de base -agrupaciones, listas, cuerpos de delegados y comisiones internas- asumían un papel fundamental en su concepción de democracia sindical. Según los documentos, las bases obreras debían ser las que establecieran las normas que ajustaran el funcionamiento de los sindicatos y, en ese sentido, los espacios de base aparecían como los organismos a fortalecer debido a que eran considerados como los más propicios para garantizar la participación directa de los trabajadores en las decisiones, y también para controlar las "manipulaciones burocráticas". En ese sentido una de las garantías de la democracia sindical era la lucha contra el "dirigentismo", es decir, contra la tendencia a reducir la actividad sindical a las negociaciones con las patronales, sin promover la participación, organización y la movilización de las bases. ${ }^{13}$ En ese marco el delegado de fábrica asumía un papel fundamental ya que era quien tenía menos posibilidades de despegarse de las bases, dependía del reconocimiento directo de sus compañeros de trabajo y podía ser controlado y revocado fácilmente por estos. Esta perspectiva queda clara en un documento titulado "Qué importancia tiene y cómo debe ser un delegado clasista” publicado por la Mesa Regional de la Zona Sur del MSB. En él se resalta el lugar clave que ocupaba el delegado en tanto representante de secciones de fábrica -espacio donde la contradicción entre la patronal y la clase obrera se hacía evidente-. Asimismo se exponen 
las características ideales que, para el MSB, deberían tener estos representantes, entre los que se destacan: estar unidos constantemente con sus compañeros de trabajo, reflejando sus necesidades y llevando adelante sus derechos a pesar de cualquier dificultad que se presente; no perseguir nunca objetivos personales y rechazar todo intento de persuasión por parte de la patronal; sostener una posición antipatronal y antiimperialista y defender la democracia sindical haciéndola respetar consultando permanentemente a las bases. ${ }^{14}$

Detrás de la idea de delegado clasista se resumían los núcleos centrales del modelo sindical que propugnaba el MSB y, a través de él, el PRT-ERP. En oposición al "modelo burocrático", el cual era asociado a la "manipulación", la "corrupción", el "beneficio personal", "las negociaciones a espaldas de los trabajadores", etc., el delegado y el sindicato clasista debían caracterizarse por la "honestidad", la "representatividad", la "solidaridad de clase", "el respeto a la decisión de las bases", la "disposición a la lucha”, etc. Desde esta visión ningún delegado, aún surgido de la lucha antiburocrática, estaba exento de una posible "burocratización”, y la única garantía de evitarlo era con la participación directa de las bases en la toma de decisiones.

En ese sentido, siguiendo a Farace y Jäkel, podemos decir que desde esta concepción, que con matices atravesaba a todas las vertientes de la nueva izquierda, la "democracia sindical" y la "lucha" eran dos conceptos inseparables y en ellos subyacía el supuesto de que la "verdadera" representación de "los intereses" de los trabajadores conllevaba la confrontación directa con la patronal, la burocracia o el Estado (2016, p. 166). De esta manera, los delegados aparecían como el arma de los clasistas desde la cual construir las fuerzas necesarias para ganar los sindicatos, ya que aquellos, supuestamente, eran más difícilmente controlables por la "burocracia" y por ende su eslabón más débil.

Por su parte, el programa del MSB contenía denuncias, reivindicaciones permanentes y un plan de lucha que intentaba contener las reivindicaciones inmediatas. Lo primero que denunciaba era el Pacto Social y desde allí se criticaba fuertemente a la Ley de Asociaciones Profesionales -que fortalecía las cúpulas sindicales-y de Prescindibilidad - que facilitaba los despidos masivos-a la vez que hacía foco en las reformas al Código Penal. En la lista de reivindicaciones permanentes se exigía la derogación de la legislación represiva, el mejoramiento de las condiciones de vida y de trabajo (en las que figuraba principalmente el reclamo por vivienda digna, fuentes de trabajo, salud gratuita y derechos cívicos) y el ejercicio de la democracia sindical (este último se erigía como punto central). Por último, se incorporaban las exigencias del control obrero de la producción, la libertad a los presos políticos, la convocatoria de las comisiones paritarias nacionales para la discusión de los convenios colectivos, el aumento de los salarios y el retiro de las fuerzas policiales de los lugares de trabajo.

De acuerdo con sus estatutos el MSB podía estar integrado tanto por personas físicas en calidad de trabajadores en relación de dependencia, así como colectivamente a través de agrupaciones gremiales o sindicales de obreros o empleados. El mismo estaba conformado en base a una estructura federativa nacional integrada por regionales, provinciales o zonales, delimitadas y diferenciadas por el número de sus adherentes o características socioeconómicas. La dirección nacional consistía de una Mesa Nacional compuesta por un número no menor de 5 y no mayor de 15 miembros que representaban a las diversas regionales; a su vez cada regional, en tanto dirección intermedia, elegía su Mesa Regional a propuesta de los plenarios de cada una de ellas. $^{15}$

De este modo a lo largo de 1973 se fueron desarrollando los distintos plenarios regionales en los que se conformaron las direcciones locales y se definieron los ejes básicos de organización y de lucha. Así por ejemplo, hacia septiembre de ese mismo año en la ciudad de Metán, se llevó adelante la fundación del MSB salteño y jujeño, en la que participaron representantes de la Agrupación 14 de julio del Tabaco, del Sindicato de Obreros del Ladrillo, Municipales, Sindicato Único de Obreros del Vestido, Sindicato de la Construcción, Sindicato de Obreros Gráficos, Obreros temporarios del tabaco, Sindicatos de Canillitas y Judiciales, entre otros. En él se definió la dirección de la zona, y se planteó como prioridad fundamental "rescatar la central [CGT Salta] a cualquier precio" ${ }^{16}$ 
Por su parte el 22 de diciembre del mismo año en villa Las Antenas, La Matanza, Provincia de Buenos Aires, se realizó un plenario convocado por las regionales Capital Federal y Buenos Aires con el objetivo de lograr una coordinación conjunta y resolver una misma política para la zona, avanzando en la estructura orgánica, con la creación de una coordinadora interzonal. Al mismo concurrieron cerca de 200 activistas; se discutió sobre la situación de las principales industrias de la zona, las principales luchas que se venían desarrollando en las distintas empresas y se repudió a la Ley de Asociaciones Profesionales y a la Ley de Prescindibilidad. ${ }^{17}$ En su convocatoria se resaltaban las luchas de la zona de los telegrafistas de la Seccional Sur, Yelmo, Vialidad, General Motors, empleados de Acindar, Zapeba, Peñaflor, Blindex, Cristaluz, Alpargatas, Wobron, Terrabusi, Squibb, Del Carlo, Philips, Oxigena San Justo y Santa Rosa, entre otras, en muchas de las cuales el PRT-ERP tenía un trabajo político, así como también lo empezaba a tener el MSB.

Éste último tuvo un crecimiento desigual aunque sostenido en las distintas regionales y zonas, dándose las formas organizativas más propicias en relación a los niveles de desarrollo de cada regional. Por ejemplo en Salta, donde la CGT clasista estaba integrada al MSB, logró niveles de movilización muy importantes durante esos años, pudiendo coordinar medidas de lucha con varios sindicatos. En Tucumán se conformó una Mesa Regional desde la cual se impulsó una activa participación en diversas luchas obreras entre las que se destacaron el conflicto azucarero ${ }^{18}$ y el de la planta citrícola "San Miguel”" del año 1974, así como también participó de distintos actos contra el avance represivo. Por otro lado se hallan referencias menores sobre la actividad del MSB en Mendoza (donde realizó un acto en conmemoración del 1 de Mayo junto al Peronismo de Base -PB- que concentró cerca 600 personas), Misiones y Bahía Blanca. ${ }^{20}$

La Regional Buenos Aires se organizaba a través de una mesa interzonal para trabajar en conjunto los conflictos de las zonas. La Zona Capital, por ejemplo, pequeña en relación a las otras, impulsaba una mesa coordinadora provisoria desde la cual apoyaba y participaba en varios conflictos. Esta forma organizativa mutó hacia 1974, año en que la Zona Capital, Zona Norte, Zona Oeste y Zona Sur llevaron adelante sus respectivos plenarios y eligieron sus propias mesas zonales. Por su parte, en Córdoba fue donde tuvo mayor desarrollo. ${ }^{21}$ Como indica Gregorio Flores: "El Movimiento Sindical de Base tuvo en Córdoba un crecimiento importante en gráficos, en Perkins Fiat-Concord, Materfer, Renault, en sindicatos como el caucho, lecheros, el calzado, en Luz y Fuerza" (Flores, 2013, p. 123). Su influencia se extendía a ramas como automotrices, sanitarios, lácteos, docentes, viales, gráficos, viajantes, estatales nacionales y provinciales, construcción, caucho, metalúrgicos, municipales, lucifuercistas, hospitalarios, gremios profesionales, etc. (Bohoslavsky, 2016, p. 59). De este modo se transformó en un pilar del movimiento obrero cordobés en casi todas las fábricas y conflictos gremiales e integró (y fue un actor clave en su formación) el Movimiento Sindical Combativo (MSC) junto a Agustín Tosco y René Salamanca (Pozzi, 2001). Este último era un frente intergremial organizado fundamentalmente por los sindicatos Luz y Fuerza, SMATA y Perkins, al cual se sumaron numerosos gremios como Obras Sanitarias, Caucho, Prensa, Gráficos, Viajantes, Lecheros y docentes, entre otros, y comisiones internas y agrupaciones de casi todo el ámbito laboral cordobés. El MSC actuaba como una corriente dentro de la CGT cordobesa, abarcaba a todo el sindicalismo que no estaba alineado a las dos ramas de las 62 Organizaciones, y desde ese lugar fue el que encabezó la resistencia ante la avanzada derechista en la provincia durante 1974 y el que protagonizó la coordinadora de gremios en lucha durante el año 1975.

\section{AUge, REPRESIÓN Y PARÁLISIS DE SUS ESTRUCTURAS}

Los últimos meses de 1973 y el comienzo de 1974 estuvieron marcados por una clara ofensiva de los sectores del sindicalismo ortodoxo quienes se dispusieron a avanzar desde el gobierno y los sindicatos contra todas las expresiones combativas y antiburocráticas del movimiento obrero. Entre noviembre y diciembre, con la Ley de Asociaciones Profesionales y con la consolidación de Ricardo Otero -dirigente de la Unión Obrera 
Metalúrgica (UOM) - en la cartera de trabajo, se afirmaba la importancia de la "burocracia sindical" en el esquema del gobierno, algo que se vio reflejado en el poder que fue adquiriendo la figura de Lorenzo Miguel desde la UOM y las 62 Organizaciones. Esto además iba acompañado por el recrudecimiento de la represión legal e ilegal, la persecución y el asesinato de militantes y activistas gremiales ${ }^{22}$ y las amenazas, atentados y allanamientos que sufrieron publicaciones como el diario El Mundo y las revistas Militancia y el Descamisado. ${ }^{23}$

Como parte de esta escalada, la conducción nacional de Luz y Fuerza suspendió la afiliación de la delegación cordobesa liderada por Tosco y el gremio SMATA hizo lo propio con la filial liderada por el dirigente clasista René Salamanca. Esto motivó la realización de un acto convocado por la CGT cordobesa el 14 de diciembre, en repudio al avance del "fascismo" en la provincia. De este acto participó el $\mathrm{MSB}^{24}$ que, en la versión perretista, había sido junto al $\mathrm{PB}$ y los sindicatos combativos quienes habían tenido la iniciativa y habían logrado imponérselo prácticamente a la CGT regional que no estaba convencida de convocarlo. ${ }^{25}$ Pocos meses después, el 28 de febrero de 1974, la "burocracia sindical" finalmente dio el golpe de gracia sobre la CGT cordobesa. En el marco del "Navarrazo" (golpe de Estado policial encabezado por el jefe de la policía provincial Antonio Navarro, que destituyó al gobernador Ricardo Obregón Cano y al vicegobernador Atilio López), se llevó adelante un congreso normalizador que sesionó bajo el principio de que la central obrera debía ser conducida por la ortodoxia justicialista. La presencia del ministro de trabajo de la nación y del secretario adjunto de la CGT nacional, Raúl Ravitti, tuvo el objetivo de legitimar ese proceso (Iñigo Carrera et al., 2006).

En este contexto, la regional Buenos Aires del MSB publicó una declaración donde denunciaba esta escalada represiva y donde reconocía como única autoridad representativa de la CGT regional a Tosco y a Roberto Tapia (secretario general) y al mismo tiempo hacía un llamado a la unidad de las bases para la luchar por aumentos salariales, mejores condiciones de salubridad, seguridad laboral, contra los topes de producción y por el retiro de la gendarmería de las fábricas. ${ }^{26}$ Esta declaración, a su vez, estuvo acompañada por la participación masiva del movimiento en el acto convocado por el MSC el 25 de marzo, para repudiar la intervención provincial y la "usurpación” de la CGT. Allí el MSB tuvo a Gregorio Flores como uno de los oradores centrales del acto.

Unos días después, el 13 abril, se realizó el Segundo Plenario Nacional del MSB. ${ }^{27}$ Reunidos en el Córdoba Sport, ubicado en la capital mediterránea, participaron cerca de cinco mil trabajadores en representación de ciento veinte agrupaciones sindicales, sindicatos y comisiones internas. En él se eligieron los miembros de la Mesa Nacional, quedando integrada por quince miembros ${ }^{28}$ y siendo designado Eduardo Castello (miembro del PRT-ERP) como su secretario general. Además se aprobaron oficialmente los estatutos y el programa. Por otro lado, considerando que existía una ofensiva general de sectores fascistas y burgueses dentro y fuera del Gobierno, así como también de la "burocracia sindical", y una dispersión de los sectores combativos del movimiento obrero, se resolvió hacer un llamado a todas las corrientes de este último a convocar de manera conjunta un "Gran Plenario Combativo" para definir un plan de lucha y una movilización nacional para derrotar fundamentalmente el Pacto Social.

Entre las distintas regionales que participaron, la Regional Buenos Aires contó con una cantidad considerable de asistentes, entre los que se encontraban agrupaciones de los establecimientos Rigolleau (Berazategui), SIAP, Fiat (Palomar-Caseros), A.T.E, Imperial Crod, Cildañez (Lugano), EATON (José C. Paz), Polimene (Ezpeleta), Terrabusi, Metalúrgica Karen, General Motors, Peugeot, TAMET, Kapeluz, Kodak, Miluz, Lamidesc, Matarazzo (Avellaneda), WINCO, INSUD, FATE, Santa Rosa, entre otras, así como también Comisiones Internas y delegados de distintos lugares de trabajo. ${ }^{29}$ Como muestran los informes de inteligencia de la ex-DIPBA, hubo una activa organización del MSB en el Gran Buenos Aires, del cual salieron colectivos desde distintos puntos geográficos: Zona Norte, Zona Sur, Zona Oeste del Gran Buenos Aires y de Zona Capital Federal. ${ }^{30}$ 
Aquel acto representó el punto máximo del desarrollo del MSB a nivel nacional y, al mismo tiempo, un punto de inflexión en su amplitud y perspectiva. El plenario cristalizó un año de trabajo y crecimiento general donde las diferentes regionales se fueron formando, llevado adelante las instancias de plenarios zonales y regionales, y participando activamente de diferentes actos y conflictos sindicales. ${ }^{31}$ Ahora bien, la actividad pública del MSB fue mermando hacia fines del año 1974 e inicios del año 1975. Consideramos que esto se debió al menos a dos factores: por un lado al aumento del clima represivo que hizo difícil el desarrollo normal de una organización que se proponía desenvolverse "en el marco de los derechos y garantías emergentes de la Constitución Nacional”. Un ejemplo de ello fue la prohibición del plenario convocado por el MSB Regional Buenos Aires ya para el 8 de junio de 1974, que pretendía llevarse a cabo nuevamente en villa Las Antenas y que fue intervenido por la policía y clausurado, acusando que los organizadores no habían pedido el permiso correspondiente a las autoridades necesarias. ${ }^{32}$ Por otra parte, como se verá en el próximo apartado, las aspiraciones del MSB de constituirse en un amplio movimiento gremial chocaron con el control "administrativo" y el excesivo "hegemonismo" del PRT-ERP que lo llevó, sobre todo en este último año, a una parálisis de sus estructuras.

Durante el año 1975 el MSB logró tener distintos niveles de presencia en las luchas obreras, sobre todo en Córdoba, participando en la Mesa Previsora de Gremios en Lucha, desde donde a través del MSC se impulsaron y condujeron las grandes movilizaciones de las automotrices Perkins, Transax, Grandes Motores Diesel y Thompson Ramco. No obstante, en cuanto a las coordinadoras interfabriles del Gran Buenos Aires su intervención es difícil de rastrear ya que no existen demasiadas fuentes que demuestren su participación efectiva, más allá de algunas referencias (Löbbe, 2006). De hecho durante ese año no se registran nuevos plenarios regionales o reuniones públicas, y tampoco se realizó el III Plenario Nacional, algo significativo ya que los plazos estipulados estatutariamente marcaban una periodicidad de Plenarios Nacionales anuales y Plenarios Regionales cada tres meses. Por su parte, hacia agosto el propio PRT-ERP hacía un llamado a su militancia fabril a "revitalizarlo", ${ }^{33}$ por lo que es probable que en esos momentos la intervención del MSB se haya reducido casi exclusivamente a la intervención de dicho partido, situación que se extenderá hasta su extinción definitiva.

\section{El MSB DEVIENE EN BRAzo SINDICAL DEL PRT-ERP}

El MSB fue pensado por el PRT-ERP como la forma más acabada de llevar adelante una política de democracia sindical clasista, lo que significaba que la amplitud debía ser el rasgo fundamental del movimiento. Esto se refleja en sus estatutos, en los que queda en claro que el MSB no pretendía ser la herramienta de una corriente política, sino una alternativa de organización y combate para las más amplias masas obreras, con sus distintas tendencias políticas.

En el plano de las fuerzas sindicales, el PRT-ERP tenía una caracterización acabada de cada uno de los espacios que formaban parte del amplio abanico de corrientes antiburocráticas. En ese sentido la organización definía seis nucleamientos principales: 1- el "reformismo", en el que ubicaba al Movimiento Nacional Intersindical, corriente impulsada por el Partido Comunista, que era caracterizada como una fuerza sindical que agrupaba un sector de la clase obrera dispuesto a la lucha reivindicativa pero cuya determinación y definición netamente combativa variaba según el avance de la lucha de masas; 2- los "espontaneístas", calificativo con el que identificaban a las corrientes dirigidas por las organizaciones trotskistas y que, a los ojos perretistas, se caracterizaban por su marcado sectarismo; 3- la corriente liderada por Agustín Tosco, quien era definido como uno de los dirigentes más destacados del país y uno de los responsables de la experiencias del MSC; 4- las agrupaciones lideradas por el PB, que eran vistas como el sector más avanzado del peronismo revolucionario por dar muestras efectivas de independencia de clase; 5- la Juventud Trabajadora Peronista brazo sindical de Montoneros-, analizada como la corriente sindical más reticente a romper "definitivamente 
con la conducción burguesa del movimiento obrero y avanzar hacia el frente contra la burocracia"; y por último 6- el MSB. ${ }^{34}$

Estos, según Luis Mattini, excepto los trotskistas, eran los aliados considerados principales para la actividad sindical perretista, y por ende los principales aliados para la política del MSB (Mattini, 2007, p. 184). No obstante, el MSB solo logró nuclear algunos agrupamientos políticos de izquierda como el Grupo Obrero Revolucionario (GOR), ${ }^{35}$ Orientación Socialista, ${ }^{36}$ Liga Espartaco y el Partido Comunista Marxista Leninista (PCML), ${ }^{37}$ y si bien contó con la participación y adhesión en sus actos del FRP, las FAL (Columna Lescano-Polti-Taborda, Columna América en Armas y Columna Che Guevara), la Juventud Radical Revolucionaria y la sección tucumana del $\mathrm{PB}$, estos grupos nunca terminaron de incorporarse formalmente. El hecho de que no lograra incorporar a fuerzas políticas como el PB o incluso de formalizar la participación del FRP, que en la práctica eran los principales aliados, fue una clara muestra de las deficiencias políticas que tuvo la experiencia. En la práctica, y a contrapelo de sus objetivos y definiciones, el MSB se transformó en el brazo sindical del PRT-ERP. Así lo indica el testimonio de Luis Mattini:

en el MSB se juntaba la gente que no era perro pero movía la cola, o sea que no se identificaba como PRT por las razones que fueran pero bueno, simpatizaban, estaban tan cerca que... bueno algunos grupos que tendría que acordarme, este... OCPO... a veces hemos tenido tareas en común con el PST, pero era muy difícil, depende dónde... en general era agrupar todo lo que estuviera contra la burocracia sindical. Y bueno el MSB, claro, tuvo el desarrollo donde había gente del PRT (...) ${ }^{38}$

La amplitud se transformó así en la dimensión más problemática para la organización, lo que la llevó en muchos casos a transformar al MSB en un sinónimo del PRT-ERP, desviando el sentido original por el cual el partido había impulsado dicha herramienta. Los problemas principales estaban en los criterios con los que la organización tendió a construir los espacios frentistas que afectaron la relación con las demás fuerzas políticas. Esto puede verse en el testimonio de Armando Jaime, líder de la CGT Clasista y dirigente del FRP:

(...) teníamos muchas discusiones con ellos... cuestiones que yo a veces les planteo a los compañeros cuando hacíamos política de alianzas. Había muchas discusiones con ellos en torno más que todo a la metodología, al respeto mutuo entre las organizaciones, todo eso, que a veces a nivel de la dirección de ellos, ellos lo comprendían y lo manifestaban y daban directivas, pero muchas veces en la base, en la militancia común se comenten errores ¿̨no? De atropello... ${ }^{39}$

En ese sentido, Gregorio Flores reconstruye las prácticas militantes que llevaron, en varios casos, a que algunas fuerzas se sintieran "atropelladas" por el PRT-ERP al interior de los espacios frentistas:

En el MSB existía el mismo criterio que en la conformación del FAS. La orientación general la daba el PRT; luego en las reuniones con los distintos frentes se informaba lo que sucedía en cada fábrica, obra, talleres, etc., y ahí se sacaban las tareas a realizar (volantes, piquetes, etc.). El PRT era, por lejos, la organización que movilizaba la mayor cantidad de militantes, y simpatizantes y también la más conocida y respetada por su conducta militante. En una oportunidad los compañeros de El Obrero me plantearon lo siguiente: nosotros no estamos de acuerdo con que el FAS funcione como un apéndice del PRT. Naturalmente, llevé esta inquietud a la dirección del PRT y el Negro Mauro me respondió lo siguiente: 'El PRT pone el 80 $\%$ de los militantes, el $80 \%$ de los locales y el $80 \%$ de la guita. Entonces, con todo derecho tiene que poner el $80 \%$ de la política.' Cuando le conté esto a los compañeros de El Obrero, ellos me dijeron: 'Sí está bien, pero así no se construye un frente.'. Poco tiempo después El Obrero se fue del FAS. (Flores, 2013, p.125).

Aquí se evidencia una forma esquemática de entender la dirección de un espacio político que parece haber obstruido también la incorporación de nuevos aliados al MSB. Creemos que fue ese mismo criterio el que llevó al PRT-ERP, por ejemplo, a hegemonizar la Mesa Nacional, siendo parte de ella con doce de sus quince miembros, y negándose a elevar su número de integrantes para que participasen cuatro agrupaciones que habían pedido formar parte (De Santis, 2010, p. 377). Por otro lado también se rechazó la participación del PRT-Fracción Roja, ${ }^{40}$ reciente desprendimiento partidario (Flores, 2013, p. 73), algo que probablemente no hubiese sucedido si no hubiera existido un control político absoluto de los perretistas.

Esta forma de dirigir el espacio no coincidía con los criterios que la misma organización planteaba en sus documentos, sino que más bien parecían ser los opuestos. El MSB debía ser la instancia organizativa desde 
la cual invitar y organizar a la mayor cantidad de organizaciones y dirigentes sindicales que coincidieran con las bases del programa antiburocrático, incluso aquellos que a sus ojos poseían "desviaciones sindicalistas" o "reformistas", buscando canalizar todos los aportes positivos que pudieran realizar, y hasta ofreciéndoles espacios de dirección en caso de que sean representativos. Según los documentos, la militancia perretista debía guiarse por una profunda flexibilidad táctica en materia de alianzas que le permitiera extender, ampliar y organizar a la mayor cantidad de tendencias obreras y trabajadores posibles. El desafío que estos militantes debían enfrentar pasaba por promover la incorporación de las más diversas corrientes clasistas, sin perder la dirección política del movimiento y sin caer en prácticas burocráticas para lograrlo. La dirección partidaria advertía este riesgo cuando sostenía:

Muchos compañeros plantean la necesidad de garantizar una esfera de influencia. Muchos compañeros plantean la necesidad de garantizar la dirección de este movimiento. Desde luego que se debe hacer, pero no por el método administrativo ni llevándolos a que se separen, sino en base a la aplicación de nuestra línea, en base a la presentación a los organismos de dirección del movimiento, de propuestas y planes correctamente preparados, que es la mejor forma de evitar el "fantasma" de que estos grupos nos lleven a discusiones estériles, imponiendo razonablemente los verdaderos ejes de trabajo, y distribuyendo los esfuerzos entre todas las organizaciones que participan, convenciéndolos de la necesidad de encarar seriamente el trabajo práctico, de manera que la dirección del movimiento se ejerza políticamente. ${ }^{41}$

En la diferencia entre dirigir políticamente y dirigir administrativamente se jugaba la capacidad que tenía la organización para construir un espacio frentista. Si el PRT-ERP pretendía transformarse en el articulador de una herramienta que se erigiera como una alternativa nacional del sindicalismo combativo, lo cual suponía incorporar necesariamente fuerzas políticas que pudieran disputarle la política del espacio, debía procurar y saber construir consensos, cediendo espacios de poder al interior del movimiento. En tal sentido, a mediados de 1974, la dirección sostenía:

La pertenencia de tal o cual partido político peronista, o de izquierda, no podía ser un obstáculo para la incorporación de compañeros, muy por el contrario se debía tratar de unificar a aquellos que con estrategias distintas, pero con coincidencias en el terreno sindical estuvieran dispuestos a participar. De esto se desprende claramente el carácter amplio del movimiento, su funcionamiento legal, su iniciativa unificadora. Pero la práctica, si bien demuestra un crecimiento óptimo, ha llevado al Partido, fundamentalmente por responsabilidad de la dirección, a desvirtuar los motivos iniciales, y sectarizar al mismo. ${ }^{42}$

La persistencia de prácticas sectarias llevó a hipotecar la amplitud y la "política de influencia” que el partido entendía como fundamental para ampliar su política y transformarse en la dirección del movimiento obrero clasista y combativo. De este modo las prácticas "hegemonistas" del PRT-ERP fueron transformando al MSB en un organismo "parapartidario", al punto de generar una identificación casi mecánica entre ambos espacios. Esto queda claro en los siguientes testimonios que reflejan cómo se construía en la práctica esa mimetización que distorsionaba los objetivos originales del espacio:

Por ejemplo, en un club en Córdoba se hace el encuentro del MSB... todo el estadio lleno, ; todo el mundo con banderas del ERP! Y gritando ipor el ERP y la Revolución! (...) ¡Mal hecho! ¡Equivocado! Porque ese es un congreso del MSB no del ERP, así seamos todos militantes del ERP, ¿te das cuenta donde está la confusión? (...) Yo tenía una agrupación gráfica acá en Rosario, éramos setecientos compañeros y yo era el que lo lideraba (incluso le saque la adhesión al MSB) entonces fuimos a Córdoba, y cuando los compañeros que no eran del ERP vieron eso me dicen ‘ ¿flaco dónde nos trajiste?, ¿estás loco vos? Yo me voy' ¿te das cuenta? (...) porque escuchame 'yo vine a un congreso sindical, yo estoy en contra de la burocracia sindical, estoy en contra de la mafia sindical, estoy a favor de Tosco, estoy a favor de Ongaro, ipero no quiero agarrar los fierros!' Es suficiente con que esté en un acto del MSB. ${ }^{43}$

En el mismo sentido otro testimonio apunta: "Yo leía lo que eran las resoluciones, lo que era y para qué era el Movimiento Sindical de Base, era una cosa distinta a lo que después era. Porque si terminaba cantando la marchita del ERP, era una cagada." (Pozzi, 2012, p. 212).

Un repaso por algunas de las consignas coreadas durante el plenario de 1974, y registradas por la revista del MSB Cuadernos de información popular, confirma el claro contenido perretista que tuvo aquel acto: "iSalta, 


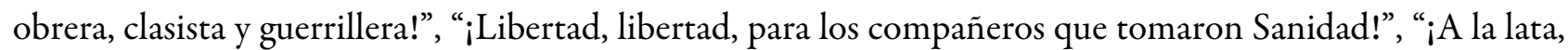
al latero, mi mamá tiene un hijo guerrillero!”, “¡Revolución o muerte, Tucumán presente!”, “¡Al socialismo, una vía, lucha armada contra la burguesía!”, “¿Cinco por uno, no va a quedar ninguno, tenemos los fusiles del 141!" (De Santis, 2000, p. 209).

Advertido del rumbo que había tomado el MSB, el Comité Ejecutivo de junio de 1974 resolvía "dar una dura batalla interna contra la desviación de origen pequeño burgués del sectarismo, por entrañar un grave peligro a la aplicación de la política de alianzas del Partido y a la educación de nuestros militantes" ${ }^{44}$ Esas directivas, no obstante, no alcanzaron para revertir la situación, ya que el MSB no tendió a incorporar a nuevas fuerzas políticas y sindicales. Ahora bien, si nos concentramos en el primer testimonio, se ve que allí el problema de la mimetización entre el MSB y el PRT-ERP no sólo afectaba la relación o la incorporación de fuerzas aliadas, sino a los propios trabajos de base. Como vimos, la línea sindical de la organización suponía que la intervención en este plano se debía dar a través de las agrupaciones o a través de espacios más amplios (como Comisión Interna, Cuerpo de Delegados, etc.), en los que no necesariamente fuera conocida la pertenencia partidaria del militante perretista. De esta forma no todos los trabajadores que participaban de las agrupaciones impulsadas por la organización, o que se identificaban con tal o cual referente sindical, adscribían a la política del partido. Si el objetivo era poder organizar a la mayor cantidad de trabajadores, estuviesen de acuerdo o no con la lucha armada, sean o no peronistas, se identificasen o no con la política del PRT-ERP, un plenario sindical no podía adquirir un tono partidario. Esto resulta significativo si se tiene en cuenta que había sido la propia organización la que a través de Gregorio Flores se había encargado de aclarar y advertir, en la apertura del plenario de fundación, que no se aceptarían actitudes y discusiones que desvirtuaran y confundieran los objetivos del movimiento con los de los partidos que intervenían en ella.

Ahora bien, la dificultad de disociar los espacios residía también en el hecho de que gran parte del desarrollo, de las tareas y de la militancia del MSB eran garantizadas por los militantes perretistas que por momentos vivían la contradicción hasta en pequeños hechos de su militancia cotidiana:

Era difícil, y salir a pintar... que se yo... vamos a una campaña de pintada del MSB, salíamos a pintar por el MSB, pero ya que está pintamos PRT, (risas) pintamos viva este, viva... Qué se yo, era lo normal, te dabas cuenta con un mismo aerosol pintabas MSB, PRT, ERP, las consignas del MSB, por ahí pintabas alguna consigna del PRT. Era medio imposible deslindarlo, para nosotros, separar una cosa de la otra. ${ }^{45}$

Estas prácticas fueron confundiendo de a poco el carácter del MSB. Sin embargo, es necesario remarcar que la capacidad de nuclear expresiones diversas que hicieran del MSB algo más que una agrupación impulsada por el PRT-ERP varió dependiendo de las zonas. Córdoba, en ese sentido, fue el caso más exitoso ya que permitió organizar a un conjunto importante de agrupaciones, Comisiones Internas y sindicatos que escapaban del control directo de los perretistas, permitiéndole adquirir una dinámica propia y participar, con un rol protagónico, en el MSC y de las coordinadoras de gremios en lucha que surgieron durante el año 1975. Pero en el resto de las regionales las características del MSB fueron diferentes. En zonas como Rosario, Tucumán y Chaco su inserción no fue mayor a la que poseía el PRT-ERP. En el caso del Gran Buenos Aires la situación no fue muy diferente. Como remarca el siguiente testimonio, en la Zona Sur del Gran Buenos Aires el MSB era activo, pero al mismo tiempo no se dejaba ver demasiada diferencia entre el partido y el movimiento:

Yeyo: (...) bueno yo entré a trabajar clandestino en una fábrica de bulones en Lanús. Desde allí atendíamos distintas fábricas, una de ellas SASETRU, la otra Rigolleau (allí recuperamos el gremio con la lista Naranja), también atendía SAIC, Collino, Duperial, Oslon, Alpargatas, Peugeot. ${ }^{46}$

Entrevistador:- ¿Todo eso era de mucha influencia del PRT?

Yeyo: De mucha influencia del PRT. Logramos que Racing nos prestara las instalaciones de la avenida Mitre y ahí hicimos un congreso del MSB. ¡Era impresionante la cantidad de compañeros que teníamos y cómo trabajábamos! (...) Por esa zona pasaron muchos compañeros que forjaron el PRT. Teníamos mucho prestigio en todas las fábricas. ${ }^{47}$ 
Por su parte, la Zona Capital Federal del MSB participó a través de la mesa coordinadora construida hacia fines de 1973, por ejemplo, en los conflictos de Citoplast, Sapeba, metalúrgica Santa Rosa y el Banco Mercantil. ${ }^{48}$ Sin embargo, era una agrupación más y con estrecho control del PRT-ERP.

Por otro lado en La Plata, según Pablo Pozzi, el MSB nunca pasó de ser un embrión de organismo gremial basado, sobre todo, en los militantes del PCML (Pozzi, 2001, p. 326). Esto se ve reflejado en el testimonio de Daniel De Santis quien remarca que no era la herramienta desde la cual se intervenía como perretistas: “Acá no llego el MSB, donde funcionaba era en Córdoba. Acá fue incipiente, no es que hubo una mesa del Movimiento Sindical de Base en La Plata, eso no hubo...". 49

Esta dinámica fue llevando a la paralización de las estructuras de dirección del MSB, tanto la nacional, como las regionales y zonales, ya que, de facto, por su composición, se habían transformado en reuniones del PRT-ERP y la exigencia de sus militantes en tareas del partido llevaba muchas veces a que estas instancias no sean garantizadas.

Por esta razón el Comité Ejecutivo de junio de 1974 había instado a la reorganización de las reuniones con “compañeros no partidarios", pero la directiva parece no haber surtido efecto, ya que hacia agosto de 1975 el partido llamaba a la "revitalización" del espacio (Leiva Flores, 2007):

Al mismo tiempo es necesario actuar rápidamente en la revitalización del MSB, dado el prestigio que este conserva en el seno
de las masas y la vanguardia, para ello lo principal es su presencia en todas las fábricas, no olvidemos que la presencia de la
actividad del Partido en lo específicamente sindical la hacemos a través del MSB o de las agrupaciones en las cuales trabajamos.
Por eso tenemos que tomar con decisión la tarea de que todo volante de carácter sindical firme el MSB o las agrupaciones.
Paralelamente hablar seriamente con los aliados viejos y nuevos, para darle un buen impulso en la superestructura. Tener
profundas charlas con ellos entusiasmándolos ante la perspectiva de apertura democrática que permitirá actos masivos del
MSB. Ser honestamente autocríticos en nuestras actitudes anteriores pero firmes en la discusión de los principios políticos.

Ahora bien, la realidad era que la intervención sindical del PRT-ERP no se daba necesariamente a través del MSB. En la práctica no era la única forma a través de la cual daba la disputa sindical en la fábrica. Como vimos, en aquellos casos en que no se había logrado construir o no se había impulsado una agrupación sindical propia o del MSB, los militantes perretistas intervenían directamente en los Cuerpos de Delegados, Comisiones Internas o comités de lucha o bien en listas sindicales amplias que, por su composición, no podían asumirse parte del MSB y tampoco constituirse en agrupaciones. Llegar a desarrollar una agrupación propia o del MSB dependía de las condiciones políticas de la zona y las fábricas donde se actuaba, y estas variaban según múltiples razones: el nivel de desarrollo político alcanzado en esas fábricas, ${ }^{51}$ o las posibilidades de coordinación que pudieran lograr con las otras organizaciones.

Un caso ejemplar en ese sentido fue el de Villa Constitución durante 1974. En el marco del llamado "Villazo", el MSB organizó la solidaridad de múltiples agrupaciones y fábricas de distintos puntos del país que mostraron su apoyo a la lucha de los obreros metalúrgicos de la localidad. ${ }^{52}$ De hecho la Regional Buenos Aires y la Regional San Nicolás del MSB participaron con importantes delegaciones del Plenario Nacional Antiburocrático convocado el 20 de abril con ese mismo objetivo. Sin embargo, durante el conflicto, en Villa Constitución habría existido una discusión entre militantes perretistas sobre cuál debía ser la herramienta sindical que debía desarrollarse entre los obreros de la localidad. Así Ángel Porcu, responsable del PRT-ERP en la ciudad, habría recibido la directiva de impulsar el MSB como agrupación sindical a la par de que se estaba desarrollando la lista Marrón, lista amplia en la que participaban múltiples sectores, entre ellos peronistas. ${ }^{53}$ Esta directiva, de hecho, atentaba contra la experiencia de "la Marrón”, ya que, en la práctica, las tareas que podía y debía asumir el MSB estaban siendo desarrolladas por aquella; y, además, porque la lista, debido a su heterogénea composición, no podía encuadrarse bajo la estructura del MSB. ${ }^{54}$ En consecuencia la directiva no fue aceptada por la militancia perretista, ya que se trataba de una línea que no se ajustaba a las necesidades y la realidad concreta, más allá de ser una de las tareas que imponía el partido, de modo que el PRT-ERP continuó interviniendo sindicalmente sólo desde "la Marrón" (Winter, 2010, pp. 75-76). 
Este episodio parece mostrar que, más allá de discusiones y exigencias partidarias, las formas de intervención estaban dadas por la particularidad de cada uno de los espacios de trabajo y, si en muchos casos no se podía implementar las propuestas del partido, los militantes hacían lo que podían en el marco de las posibilidades que ofrecía el lugar de trabajo en el que se desempeñaban. Mientras que para algunos el MSB podía ser la herramienta adecuada para ampliar el trabajo y la influencia del partido, para otros podía no ser necesario utilizarla o, más aún, podía transformarse en un obstáculo para su desarrollo.

Lo anterior puede contribuir a explicar los desiguales niveles de desarrollo alcanzados por el MSB entre los años 1973 y 1974, a la vez que expone las dificultades que el PRT-ERP tuvo para revitalizarlo en 1975.

Si bien la debilidad del MSB no dificultó la inserción fabril y la participación protagónica del PRT-ERP en los principales conflictos obreros, ya que, como se dijo, la organización intervino en ellos de diferentes formas, sí debilitó la posibilidad de forjar un espacio más amplio de coordinación nacional. De hecho, una de las búsquedas principales de los perretistas durante los años 1974 y 1975 fue la de conformar un Frente Nacional Antiburocrático donde reunir y organizar a las corrientes político-gremiales más influyentes, tarea para la que en un principio había sido pensado el MSB.

\section{ConCLusión}

El MSB fue una experiencia gremial que formó parte y fue hija del campo sindical clasista y antiburocrático que emergió en la década del 70; pero, al mismo tiempo, debe ser entendido como la apuesta de una organización armada -el PRT-ERP- que, intentando aprovechar el auge de las luchas reivindicativas desatado en la coyuntura de 1973, buscó reunir en un mismo organismo y con un mismo programa a referentes, activistas sindicales y agrupaciones clasistas con trayectorias previas o en pleno desarrollo.

Como movimiento sindical el MSB logró, en un corto tiempo, considerables niveles de organización e intervención. Esto se vio reflejado en su poder de convocatoria, manifestado en sus dos plenarios y en la participación de importantes referentes sindicales, agrupaciones y comisiones internas. Además logró presencia en varias provincias, siendo protagonista en las luchas obreras de Córdoba y conteniendo en su seno a varias de las experiencias combativas más avanzadas del país.

No obstante, ese crecimiento e inserción dependió en forma directa del desarrollo y la inserción que logró el PRT-ERP en las principales fábricas, lo que le impuso un límite orgánico y político. Y es que más allá de que en el MSB participaron otras corrientes políticas - de notable menor peso- la influencia de los perretistas en su dirección fue decisiva. Ello, además, se vio agravado por la manera esquemática, "administrativa" y hegemonista en la que lo dirigieron, lo que llevó a que rápidamente se transformase en una herramienta prácticamente "parapartidaria" y, por ende, a que se viera hipotecada la amplitud con la que se había pensado e impulsado.

Consideramos que este proceso puede explicarse, en parte, por un fenómeno que atravesó a todas las organizaciones de la izquierda -marxista y peronista- de los años 70, y que se profundizó a partir del retorno del peronismo al poder: el que las diferencias estratégicas oficiaran de parteaguas y obstáculo incluso en instancias en las que -al menos teóricamente- podrían no haberlo sido, como en la sindical. De este modo, la unidad de acción que se dio en los hechos al interior de las fábricas entre los militantes de base de las diferentes organizaciones, manifestada entre otras cosas en el surgimiento de listas o agrupaciones amplias, no pudo materializarse en acuerdos que fueran más allá de las mismas, limitando seriamente la posibilidad de disputar la conducción de sindicatos nacionales y más aún de la propia CGT. Ello repercutió fuertemente en el PRTERP que, en su afán de referenciarse como alternativa para el movimiento obrero -y ante el crecimiento de espacios como la JTP montonera-, terminó transformando al MSB en su brazo sindical y demostrando serias dificultades para sostener una política de alianzas que le diera espacio a organizaciones que pudieran cuestionar su política. Eso fue un límite evidente para el MSB que vivió una parálisis de sus estructuras, e incluso a veces resultó un obstáculo para la propia intervención sindical de los militantes fabriles del PRT- 
ERP quienes, como en el caso de Villa Constitución, elegían no construir aquella herramienta para lograr construir espacios más amplios.

En este artículo hemos avanzado en la reconstrucción historiográfica del MSB, analizando sus objetivos, su concepción sindical y su planteo programático; además hemos repasado, a grandes rasgos, su derrotero durante los años 1973-1975. Asimismo hemos analizado en profundidad la forma en que el PRT-ERP intervino en su seno y las dificultades que tuvo a la hora de articular con el resto de los actores que participaron en él. Queda planteado, entonces, un estudio sistemático de cada una de sus regionales ${ }^{55}$ para conocer más acabadamente la experiencia y los niveles de influencia reales que llegó a ejercer en las principales luchas obreras del país.

\section{Bibliografía}

Basualdo, V. y Lorenz, F. (2012). Los trabajadores industriales argentinos en la primera mitad de la década del '70: propuestas para una agenda de investigación a partir del análisis comparativo de casos. Revista Digital de la Escuela de Historia, 4(6), 123-157.

Bohoslavsky, A. (2016). Los Cheguevaristas. La Estrella Roja, del Cordobazo a la Revolución Sandinista. Buenos Aires: Ediciones Imago Mundi.

Brennan, J. (1996). El Cordobazo: guerras obreras en Córdoba, 1955-1976. Buenos Aires: Editorial Sudamericana.

Casco Peeble, M. y Lenuda, M. A. (2016). Conflicto obrero y acción guerrillera. La huelga en Mercedes Benz en 1975 y el secuestro de un nazi. Archivos, 5(9), 97-116.

Dawyd, D. (ed.) (2017). Si trabajo me matan. Las huelgas metalúrgicas en La Matanza en 1974: Insud, Martín Amato y Santa Rosa. San Justo: Universidad Nacional de La Matanza.

De Riz, L. (1987). Retorno y Derrumbe. El último gobierno peronista. México: Editorial Hyspamerica.

De Santis, D. (2000). A vencer o morir. PRT-ERP. Documentos, Tomo II, Buenos Aires: Eudeba.

De Santis, D. (2006). A vencer o morir. Historia del PRT-ERP. Documentos, Tomo I, Vol. 2, Buenos Aires: Nuestra América.

De Santis, D. (2010). La historia del PRT-ERP por sus protagonistas. Buenos Aires: A formar filas editora guevarista.

Della Savia, G. (2017). Las luchas de los trabajadores de Del Carlo. La Roca, 4, 122-157.

Della Savia, G. (2018). Las huelgas de Matarazzo (1973-1974). La Roca, 5, 358-406.

Farace, R. y Jäkel G. (2016). Nociones sobre 'democracia obrera' y 'burocracia sindical' en la izquierda de los años 70. Una comparación entre la izquierda peronista y la izquierda marxista. Trabajo y sociedad, 26, 155-170.

Flores, G. (2013). Lecciones de batalla. Buenos Aires: Ediciones RyR.

Iñigo Carrera, N., Grau, M. I. y Martí, A. (2014). Agustín Tosco. La clase revolucionaria. Buenos Aires: Ediciones La Llamarada; Editorial Yulca; Amauta Insurgente Ediciones.

Laufer, R. (2018). El clasismo en el SMATA Cordoba. Archivos, 6(12), 121-142.

Leiva Flores, S. (2007). Teoría y práctica delpoderpopular, los casos del MIR, Chile, 1970-1973 y el PRT-ERP, Argentina, 1973-1976 (Tesis de posgrado). Universidad de Santiago de Chile, Chile.

Lenci, M. L. (1998). La radicalización de los católicos en la Argentina. Peronismo, cristianismo y revolución, 1966 1971. Cuadernos del CISH, 3(4).

Löbbe, H. (2006). La guerrilla Fabril. Clase obrera e izquierda en la Coordinadora de Zona Norte del Gran Buenos Aires (1975-1976). Buenos Aires: Ediciones RyR.

Lorenz, F. (2013). Algo parecido a la felicidad. Una historia de la lucha de la clase trabajadora durante la década del setenta (1973-1978). Buenos Aires: Edhasa.

Maggio, M. (2012). Diario El Mundo: PRT-ERP: prensa masiva para una política de masas. Buenos Aires: Editorial Cooperativa El Rio Suena.

Mattini, L. (2007). Hombres y mujeres del PRT-ERP de Tucumán a la Tablada. La Plata: De la Campana. 
Pacheco, J. (2015). Análisis de la militancia sindical de Montoneros: la Juventud Trabajadora Peronista y sus luchas. e-l@tina, 13(50).

Pozzi, P. (2001). Por las sendas argentinas... El PRT-ERP. La guerrilla Marxista. Buenos Aires: Eudeba.

Pozzi, P. (2012). Historias de "perros". Entrevistas a militantes del PRT-ERP. Buenos Aires: Imago Mundi..

Pozzi, P. y Schneider, A. (2000). Los setentistas. Izquierda y clase obrera: 1969-1976. Buenos Aires: Eudeba.

Rot, G. (2016). Un balance de los estudios sobre las Organizaciones Político-Militares argentinas. Archivos, 5(9), $33-55$.

Santella A. y Andujar A. (2007). El Perón de la fábrica éramos nosotros. Las luchas metalúrgicas de Villa Constitución 1970/1976. Buenos Aires: Desde el Subte.

Scoppetta, L. y Torres, P. (2018). La política sindical del PRT-ERP: notas sobre una búsqueda (1965-1976). En S. Simonassi y D. Dicósimo, Trabajadores y sindicatos en Latinoamérica. Buenos Aires: Imago Mundi.

Silva Mariños, L. (2017). FAS Frente Antiimperialista y por el Socialismo. Un ejército politico de masas impulsado por el PRT. Buenos Aires: Ediciones La Llamarada.

Stavale, S. (2019). Perros en las fábricas: La politica sindical del PRT-ERP, sus prácticas y la experiencia de sus militantes en fábricas del Gran Buenos Aires, 1973-1976 (Tesis doctoral). Universidad Nacional de La Plata, Recuperada de http://www.memoria.fahce.unlp.edu.ar/tesis/te.1675/te.1675.pdf

Stavale, S. (2017). Entre la lucha ideológica y la unidad de acción en las fábricas. La relación del Partido Revolucionario de los Trabajadores con la Tendencia Revolucionaria del Peronismo en los años 70. Izquierdas, 36, 78-104.

Torre, J. C. (2004). El gigante invertebrado. Los sindicatos en el gobierno 1973- 1976. Buenos Aires: Siglo XXI.

Tortti, M. C. (directora), Chama, M. y Celentano, A. (codirectores) (2014). La nueva izquierda argentina (1955-1976): socialismo, peronismo y revolución. Rosario: Prehistoria Ediciones.

Vazeilles, J. G. (2006). Memorias de la militancia. Buenos Aires: Manuel Suárez Editor.

Winter, J. (2010). La clase trabajadora de Villa Constitución. Subjetividad, estrategias de resistencia y organización sindical. Buenos Aires: Reunir.

\section{Notas}

1 Es de destacar que hubieron trabajos pioneros que han hecho importantes aportes en ese sentido (Brennan, 1996; Pozzi \& Schneider, 2000; Löbbe, 2006; Lorenz, 2013).

2 Así fue que participó desde un inicio en múltiples plenarios y encuentros sindicales que apostaban a construir una coordinación nacional de las diferentes experiencias sindicales combativas: participó activamente del Congreso de Sindicatos Combativos, Agrupaciones Clasistas y Obreros Revolucionarias, convocados el 28 y 29 de agosto de 1971, del Plenario Clasista y el Movimiento de Recuperación Sindical (MRS) organizado en Córdoba hacia fines de 1971, entre otros.

3 "El triunfo electoral peronista y las tareas de los revolucionarios" El Combatiente Nro. 76. Segunda quincena de Marzo de 1973.

4 “Resoluciones del Comité Central de diciembre de 1972". En De Santis (2006, p. 208).

5 El ejemplo más resonante de esta política fue la formación del Frente Antiimperialista y por el Socialismo (FAS). El FAS fue un frente político con un amplio programa pergeñado por el PRT-ERP en julio de 1972, pero lanzado oficialmente en agosto de 1973, con el objetivo de que fuese el germen de un Frente de Liberación Nacional y Social, herramienta que la organización consideraba uno de los pilares centrales de su estrategia revolucionaria. De él participaron y adhirieron diferentes actores sociales y políticos, entre los que se destacaron el Frente Revolucionario Peronista, el MIR-Grupo El Obrero-ORPO, Agustín Tosco, Alicia Eguren, Ortega Peña, Manuel Gaggero, etc. (Silva Mariños, 2017).

6 "Resoluciones del Comité Ejecutivo del PRT" El Combatiente Nro. 77, Primera quincena de abril de 1973.

7 Este último había sido fundado en las postrimerías de 1972 por los abogados laboralistas Luis Cerrutti Costa y Felix Granovsky, con el objetivo de capacitar a dirigentes y delegados obreros de diversos gremios y de contribuir a la formación de una corriente sindical clasista independiente (Vazeilles, 2006). Luis Cerruti Costa tenía una trayectoria política de larga data: de orígenes nacionalistas y católicos, aunque también obreristas, llegó a ser Ministro de Trabajo del dictador Lonardi, asesor y abogado de múltiples sindicatos (Federación Gráfica Bonaerense, FOTIA, etc.) y formó parte del Comité de Abogados de la CGT de los Argentinos. Luego se transformó en director del diario El Mundo, vespertino 
adquirido por el PRT-ERP, en agosto de 1973, y fue un colaborador asiduo de la revista Nuevo Hombre, revista que también estaba bajo órbita perretista. Por su parte Felix Gronovsky, amigo personal y colega de Cerruti Costa, había sido militante del PC y fue parte de la experiencia editorial de El Mundo. (Maggio, 2012).

8 Para ver la lista de las delegaciones consultar: El Combatiente Nro. 82, viernes 19 de julio de 1973.

9 "Córdoba: plenario de las bases" Nuevo Hombre Nro. 44, jueves 12 de julio de 1973.

10 Es de destacar que el 15 de julio de 1973 el local de la CGT cordobesa fue copado por un grupo de la derecha denominado "Comando Resistencia" y fueron baleados los edificios de Luz y Fuerza y SMATA. Las hostilidades hacia los sindicatos y activistas "antiburocráticos" fueron in crecendo a lo largo de todo el año.

11 “Córdoba: Plenario de las bases” Nuevo Hombre Nro. 44, jueves 12 de julio de 1973.

12 "Córdoba: Plenario de las bases" Nuevo Hombre Nro. 44, jueves 12 de julio de 1973.

13 "Plenario Sindical en La Matanza" Nuevo Hombre Nro. 54 primera quincena de enero de 1974.

14 "Qué importancia tiene y cómo debe ser un delegado clasista" Nuevo Hombre Nro. 58, primera quincena de marzo de 1974.

15 MSB. Cuadernos de formación popular Nro. 1. Buenos Aires, Editora Popular Americana, abril-mayo 1974.

16 "Salta: se forma el Movimiento Sindical de Base" El Combatiente Nro. 89, 7 septiembre de 1973.

17 Nuevo Hombre, Nro. 54. 1era quincena de enero de 1974.

18 La lucha de los obreros azucareros fue paradigmática en tanto significó un enfrentamiento directo al Pacto Social ya que la reivindicación central eran aumentos salariales de más del 50 \%. El conflicto motivó el desarrollo de asambleas zonales en distintos ingenios, la convocatoria a un Congreso Nacional Azucarero, movilizaciones y paros, y la posterior intervención del sindicato por parte del gobierno nacional. Allí el MSB, que intervenía a través de la Agrupación Obrera Azucarera de Base en la que participaban los dirigentes José Amador y Leandro Fote (parte de la Comisión de Movilización de la FOTIA), no solo participó activamente de todas las reuniones y asambleas realizadas sino que logró organizar una asamblea propia de delegados y activistas en la que diseñó una propuesta de plan de lucha. Es de destacar que también editaba un boletín informativo llamado "El trabajador azucarero" (Nuevo Hombre Nro. 68, segunda quincena de agosto de 1974).

19 La planta "San Miguel” fue tomada por sus trabajadores para reclamar el pago de salarios y asignaciones familiares, el cumplimiento de los horarios y el pago de las horas extras. Luego de tres días de toma la fábrica fue desalojada por la policía provincial. Uno de los dirigentes de la fábrica fue el "Negro Miguel" quien a su vez era integrante de la mesa regional del MSB (Nuevo Hombre Nro. 69, primera quincena de septiembre de 1974).

20 Dichas referencias fueron encontradas en la sección "Crónicas de la Guerra Revolucionaria" del periódico Estrella Roja del año 1974.

21 El 19 de enero de 1974 el MSB de Córdoba realizó su propio plenario en el que participaron agrupaciones de las fábricas más importantes de la provincia. Ver: "Llama a plenario el MSB de Córdoba" El Mundo, jueves 24 de enero de 1974.

22 Un ejemplo de ello, entre otros, fue la denuncia realizada en conferencia de prensa por el MSB Regional Campana por la desaparición de Pedro Amaranto, militante de la organización, y del secuestro y la tortura de Luis Marcelo Panizza, delegado de la empresa EATON. (Nuevo Hombre Nro. 62, primera quincena de mayo de 1974).

23 El vínculo del MSB con estas publicaciones no sólo estaba dado por su afinidad política, centralmente con El Mundo y Militancia, sino a través de la Agrupación de Bases de Prensa, la cual denunció recurrentemente estos ataques (Nuevo Hombre Nro. 59 Segunda quincena de marzo de 1974).

24 El MSB también adhirió y participó del acto realizado el 24 de enero de 1974 frente al Congreso de la Nación para repudiar el intento de modificación del Código Penal ("El MSB en el acto del 24 en el Congreso" El Mundo, miércoles 23 de enero de 1974).

25 De este plenario también participaron la JP y la JTP, quienes fueron denunciadas por el PRT-ERP en su periódico El Combatiente por tener una supuesta actitud antiunitaria y "manijera” y por haber intentado copar el acto imponiendo sus propias consignas (“Actitud sectaria en el acto de Córdoba” en El Combatiente Nro. 101. Miércoles 19 de Diciembre de 1973).

26 Solicitada aparecida en Nuevo Hombre Nro. 59 Segunda quincena de marzo de 1974.

27 El mismo había sido definido desde principios de marzo en la reunión de la Mesa Nacional del MSB en la que además se hizo un balance del primer plenario y se pasó revista de la constitución de las diferentes zonas. ("Reunión nacional del MSB” El Combatiente Nro. 110, 13 de marzo de 1974).

28 "Otros sindicalistas conocidos que participaron del plenario fueron: Gregorio Flores, Domingo Bizzi y Julio Oropel (SITRAC), Leandro Fote (FOTIA), Melitón Vázques (Ingenio Ledesma), Daniel De Santis (Propulsora Siderúrgica), Miguel Ángel Bazán (Luz y Fuerza de Córdoba), Abelardo Correa (FOESYT Córdoba), Ramón Rojas (Carne de Rosario), Luis Segovia, Zenón Sánchez y Ángel Porcu (UOM- Villa Constitución). La mesa del MSB quedo integrada por Castelo, Oropel, Bizzi, Escobar, Panizza (EATON- Buenos Aires), Gonzales (SOETAP), Elías (Paraná), Carnas (Rosario), además de tres tucumanos no identificados, un trabajador rural de Chaco, Luz y Fuerza de 
Campana, Agrupación Avanzada Telefónica de Capital Federal y la Agrupación 3 de abril del Banco Nación (Capital Federal)" (Pozzi, 2001, p. 325).

29 Véase MSB. Cuadernos de formación popular Nro. 1. Buenos Aires, Editora Popular Americana, abril-mayo 1974.

30 DIPPBA, Mesa "B”, Carpeta 128. Legajo 16. Localidades Varias.

31 Ejemplo de ello fue la Regional Buenos Aires que entre 1973 y 1974 tuvo presencia destacada en distintos conflictos. Así, por ejemplo, participó con claro protagonismo del conflicto de la fábrica INSUD, productora de plomo, ubicada en la ciudad de San Justo; en la lucha de los obreros de la fideera Matarazzo, donde intervino activamente a través de la "Agrupación de Base de Matarazzo" y también externamente con reiterados apoyos y muestras de solidaridad en la puerta de la fábrica. Por otro lado participó de la lucha de los trabajadores de fábrica de electrodomésticos Winco, ubicada en la localidad de Ciudadela en Zona Oeste del Gran Buenos Aires a través del "Movimiento de Base de Winco"; de la de los obreros gráficos de IVISA a través de la "Agrupación Gráfica de Base", en la lucha de los trabajadores de prensa con la "Agrupación de Base de Prensa”, y en la lucha de los obreros de Bagley, ubicada en Capital Federal, desde la coordinadora zonal. (Nuevo Hombre Nro. 63 de la segunda quincena de mayo de 1974; Nuevo Hombre Nro. 66, segunda quincena de julio de 1974).

32 Nuevo Hombre Nro. 65, segunda quincena de junio de 1974.

33 Boletín Interno Nro. 85, 29 de agosto de 1975.

34 "Los revolucionarios y la actividad sindical" El Combatiente Nro. 120, miércoles 5 de junio de 1974.

35 El Grupo Obrero Revolucionario (GOR) se fundó en 1971 en base a una de las fracciones del PRT-El Combatiente que se desprendió de la organización en el V Congreso partidario realizado en 1970.

36 Orientación Socialista fue el resultado de una fracción interna del grupo El Obrero.

37 El PCML fue una organización de orientación maoísta fundada en 1969 en base a un grupo de militantes de la ciudad de La Plata que había sido expulsado del PC en 1963 por haber exigido poner en debate la polémica chino-soviética y la Revolución Cubana.

38 Entrevista a Luis Mattini por el autor, Buenos Aires, 2017.

39 Entrevista a Armando Jaime por el autor, Salta, 2016.

40 El PRT-Fracción Roja fue una fracción del PRT-ERP a inicios de 1973 en la zona sur de la Regional Buenos Aires de la organización.

41 Boletín Interno Nro. 61 primera quincena de junio de 1974.

42 Boletín Interno Nro. 61 primera quincena de junio de 1974

43 Entrevista a Rafael Peralta, trabajador gráfico, militante y miembro de la Mesa Sindical Nacional del PRT-ERP. Entrevista realizada por el autor, Rosario, 2017.

44 Boletín Interno Nro. 61, primera quincena de junio de 1974.

45 Entrevista a Raúl Castro, militante del PRT-ERP y trabajador de Galizia y Bargut, realizada por Andrés Carminatti, Rosario, 2008.

46 En los archivos de la ex-DIPBA se halla un volante del Movimiento Sindical de Base ligado al conflicto sindical de la fábrica Peugeot, lo que demuestra que se intervenía como tal en dicha zona. (Mesa "B", Factor Gremial, Berazategui, Carpeta 18 bis, Leg. 14.).

47 Entrevista a "Yeyo" Videla realizada por el autor, Buenos Aires, 2012.

48 Nuevo Hombre, Nro. 54. 1era quincena de enero de 1974.

49 Entrevista a Daniel De Santis con el autor, Buenos Aires, Junio de 2012.

50 Boletín Interno Nro. 85, 29 de agosto de 1975.

51 Cuando hablamos de "niveles de desarrollo" en una fábrica nos referimos a diversos factores como, por ejemplo, la cantidad de militantes y simpatizantes con que se contaba, el tipo de actividad que se había logrado desarrollar (sindical, militar, de propaganda y agitación), la referencia política construida entre los obreros, la existencia de agrupaciones independientes previas en la fábrica, la incorporación de dirigentes o activistas fabriles independientes a las filas del partido, etc.

52 “Villa Constitución: Plenario Antiburocrático", El Combatiente Nro. 115 Miércoles 24 de abril de 1974.

53 La lista Marrón había nacido como fruto del Movimiento de Recuperación Sindical (MRS) que había sido creado entre 1971 y 1972 por un núcleo de activistas de la planta metalúrgica de Acindar. De la Lista Marrón participaron militantes de diferentes organizaciones: Vanguardia Comunista, el PRT-ERP, el PB, Organización Comunista Poder Obrero (OCPO), el PST, Socialismo Revolucionario y JTP. Entre sus principales dirigentes se hallaban Alberto Piccinini (cercano a OCPO y, posteriormente, secretario general de la UOM) y Luis Ángel Segovia (militante perretista y, posteriormente, principal dirigente del Comité de Lucha) (Santella y Andujar, 2007).

54 Según Ángel Porcu algo similar le ocurría a los militantes de Montoneros quienes eran instados por su dirección a formar la Agrupación Sindical Peronista "Felipe Vallese". Según Porcu, él y Raúl Horton, delegado de Acindar y dirigente sindical montonero, habrían acordado preservar la lista Marrón y no impulsar ni el MSB ni la "Felipe Vallese” para evitar la división de la lista en múltiples tendencias (Winter, 2010, p. 76). 
Santiago Stavale. El Movimiento Sindical de Base: apuesta sindical del PRT-ERP

55 Es de destacar que en la tesis doctoral, de la cual se desprende el presente artículo, hemos avanzado en la reconstrucción del MSB Regional Buenos Aires.

\section{BY-NC-SA}

